\title{
THE NEW PHENOMENON OF LITHIUM ELECTROCHEMICAL (DE)INTERCALATION IN MINERAL CLAY MATERIALS AND THEIR POTENTIAL APPLICATION IN RECHARGEABLE BATTERIES
}

\author{
SHI-JIE WEN*, XIAO-TIAN YIN and L. NAZAR \\ The Guelph-Waterloo Centre for Graduate Work in Chemistry, University of Waterloo, Waterloo, \\ Ontario, Canada, N2L $3 G 1$
}

(Received November 17, 1993; in final form January 4, 1994)

\begin{abstract}
A new phenomenon of Li electrochemical (de)intercalation on the pure mineral clay materials has been evidenced for the first time. These tests are initialized by the idea of putting an electronic conducting polymer or a multi-valent metal oxide in the layer of the clay to modify the electronic properties and also to modulate the charge and discharge potential of the clay during the Lithium electrochemical (de)intercalation processing. In this paper, as the beginning of our research, we will first show the results of Lithium electrochemical charge and discharge processes on pure clay materials.
\end{abstract}

\section{INTRODUCTION}

For more than 15 years, much attention has been focused on the study of lithium or proton intercalation (or insertion) materials and their multi-functional applications in industry, especially in energy storage (rechargeable batteries). From the view point of the materials' composition, we can generally now divide them into three classes: (1) the layered inorganic materials $\mathrm{A}_{n} \mathrm{MX}_{2}[1-3]$, where $\mathrm{A}$ and $\mathrm{M}$ are alkaline metal and transition metal $(\mathrm{A}=\mathrm{Li}, \mathrm{Na}, \mathrm{H}$ etc; $\mathrm{M}=\mathrm{Ni}, \mathrm{Co}, \mathrm{Mo}$, Mn etc; and $\mathrm{X}=\mathrm{O}, \mathrm{S}$, Se etc.) respectively; (2) the conductive and doping allowed organic polymers such as polyacetylene, polypyrrole, polythiophene etc [4-6]; (3) hybrid intercalation composites (combination of inorganic and organic materials, of inorganic and inorganic material, or of organic and organic material) such as $\mathrm{V}_{2} \mathrm{O}_{5}+$ PPY [7], $\mathrm{MoO}_{3}+$ PPY [8], $\mathrm{Li}_{\mathrm{x} 1} \mathrm{Ni}_{\mathrm{x} 2} \mathrm{Co}_{\mathrm{x} 3} \mathrm{O}_{2}$ [9], Naflon + PPY [10] etc.

Our group has been working for several years on the third kind of materials $\left(\mathrm{MoO}_{3}+\right.$ PPY [8], $\mathrm{MoO}_{3}+$ PPV [9], $\mathrm{MoO}_{3}+$ PAN [10], $\mathrm{MoO}_{3}+$ PEO [11], $\mathrm{NiOOH}+$ polymer etc). Recently, we began to work on pure and either a polymeror an inorganic oxide-doped clay for the fundamental and practical purpose of testing the lithium electrochemical (de)intercalation process.

* All correspondences should be addressed and whose present address is 4 Colby Street, Science and Technology Center, Tufts University, Medford, MA 02155, USA. 
The research related to the energy storage application with pure and doped clay materials is only at primary stages, but some interesting results have been obtained. For instance, in order to compare the polymer-or metal oxide-doped clay materials, we have tested the lithium electrochemical (de)intercalation process on pure clay and found that pure clay could itself sustain a relatively long term of lithium electrochemical cyclability. The massive energy density can arrive at about $27($ ) to $300 \mathrm{mAh} / \mathrm{g}$ under a small applied current but there may be a possible improvement in the future. In this paper, we will show all of the corresponding results for pure clay material.

\section{EXPERIMENTAL}

\section{Materials}

All three kinds of Volclay Bentonite SPV-200), Panther Greek-200), and Super Lig were donated by the American Colloid Company, Industrial Chemical Division with the specific technique sheets. The properties of Volclay are those of montmorillonite, a clay mineral of unique characteristics, which constitutes $90 \%$ of Volclay substance. Montmorillonite has the following approximate chemical formula:

$\left(\mathrm{Al}, \mathrm{Fe}_{1.67}\right) \mathrm{Mg}_{0.33} \mathrm{Si}_{4} \mathrm{O}_{10}\left(\mathrm{OH}_{2}\right) \mathrm{Na}^{+}, \mathrm{Ca}^{++}{ }_{0.33}$

The other $10 \%$ consists of minute fragments of other minerals, the most abundant being feldspar. There are small fractions of gypsum, calcium carbonate, and quartz, and traces of partially altered volcanic glass, biotite gwca, magnetigw, limonite, hematite, leucoxene, apatite, zircon, pyrite, titanate, and tremolite.

The black carbon was purchased from AKZO Co Japan (Ketjenblack EC 600JD).

The clay and the black carbon were all dried in a vacuum at about $150^{\circ} \mathrm{c}$ for several days before using.

The propylene carbonate $\mathrm{PC}, \mathrm{LiCF}_{3} \mathrm{SO}_{3}$ and lithium metal were purchased from Aldrich Chemical Co. The $\mathrm{PC}$ and $\mathrm{LiCF}_{3} \mathrm{SO}_{3}$ were properly purified and dried before using and were stored in an Argon-filled glove box.

\section{Electrode Preparation}

The positive electrode was prepared in the following way. First, we intimately mixed the different clay powder with 20 or 40 weight percentage of black carbon, and then pressed a total of $50 \mathrm{mg}$ of powder into a small plate, $1 \mathrm{~cm}$ in diameter. Finally we dried the plates in vacuum at $150^{\circ} \mathrm{C}$ for two days and weighed them again in the argon-filled glove box. For the electrochemical lithium (de)insertion test, we used the battery cell as in Fig. 1 and put the prepared plate as a positive electrode and metallic lithium foil with a diameter of $1.5 \mathrm{~cm}$ as a negative electrode, between them we put two layers of porous PTFE $(0.025 \mathrm{~cm}$ thick with 1 micro porous) soaked with the $\mathrm{PC} / \mathrm{LiCF}_{3} \mathrm{SO}_{3}(1 \mathrm{M})$ liquid electrolyte as the separator. The entire electrochemical test was undertaken in the argon-filled glove box. 


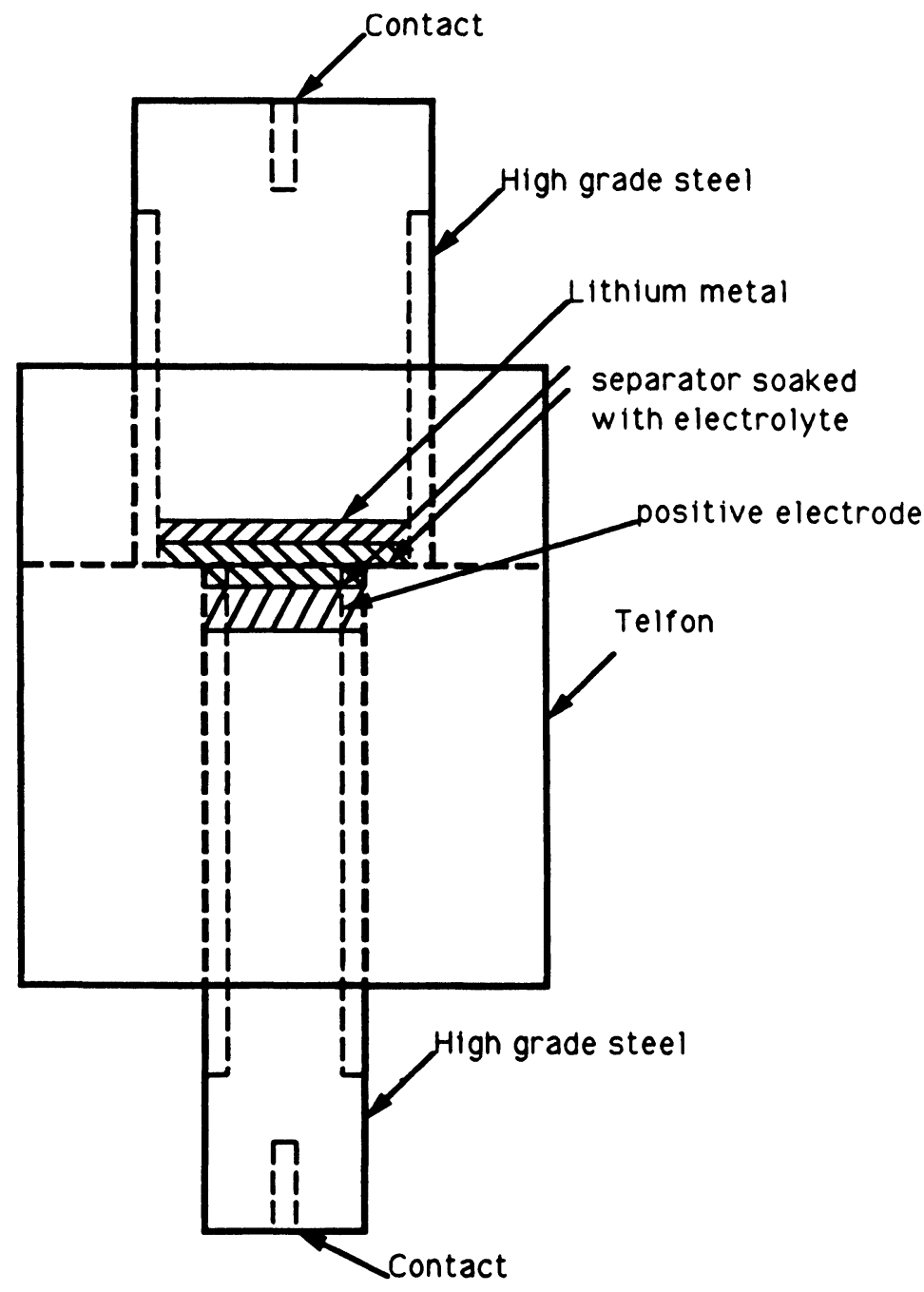

FIGURE 1 Electrochemical battery test cell.

\section{Measurements}

The lithium electrochemical testing was done by using the MacPile from the BioLogic Co. France. This equipment has 16 electrochemical testing channels controlled by a MacPile software on a Macintosh computer.

\section{RESULTS AND DISCUSSION}

All four kinds of Volclay have similar compositions and properties according to their technical sheets. SPV-200 is a low viscosity sodium bentonite exhibiting vari- 
able dry particle size and viscosity, Panther Greek 200 is a naturally occurring low or non-swelling calcium bentonite, and Super Lig is a naturally occurring alkali soluble lignite.

All of these clays also exhibit a similar possibility of $\mathrm{Li}$ electrochemical intercalation and deintercalation as shown in Figs. 2, 3, and 4. The charge and discharge potential is separated quite largely, between $1 \mathrm{~V}$ and $3.1 \mathrm{~V}$, which means the thermodynamic reversibility is not very good due to a very large structural polarization. Meanwhile, a relatively good cyclability and stability has been found. Until now it could sustain, by itself, about 50 cycles. The other interesting point from these figures is that the oxidation efficiency is nearly $100 \%$.

Fig. 5 shows the potential vs. composition, $x$, in $\mathrm{Li}_{x}$ Clay for Super Lig under a different discharge current. We can see that the lithium fraction, $\mathrm{x}$, in $\mathrm{Li}_{\mathrm{x}} \mathrm{Clay}$ can reach a value as high as 5 under $10 \mu \mathrm{A}$ discharge current and it drops to 3 and 1 when the applied currents are $30 \mu \mathrm{A}$ and $60 \mu \mathrm{A}$ respectively. Similar results were obtained for VSP-200 and Panthergreek-200. If we assume that the average charge potential is about $1 \mathrm{~V}$, the massive energy density is about 270 to $300 \mathrm{mAh} / \mathrm{g}$ under the applied current of $10 \mu \mathrm{A}$.

To see the influence of the black carbon with clay SPV-200, we have compared the galvanostatic test results for the electrodes with different weight percentages of black carbon as shown in Fig. 6. For the sake of clarity, the pure black carbon was also tested and the result shows that the (de)insertion of lithium took place below $0.4 \mathrm{~V}$ vs $\mathrm{Li}_{+} / \mathrm{Li}$ with a very small $\mathrm{x}$ in $\mathrm{Li}_{\mathrm{x}}$ Carbon. From Fig. 6 we can see

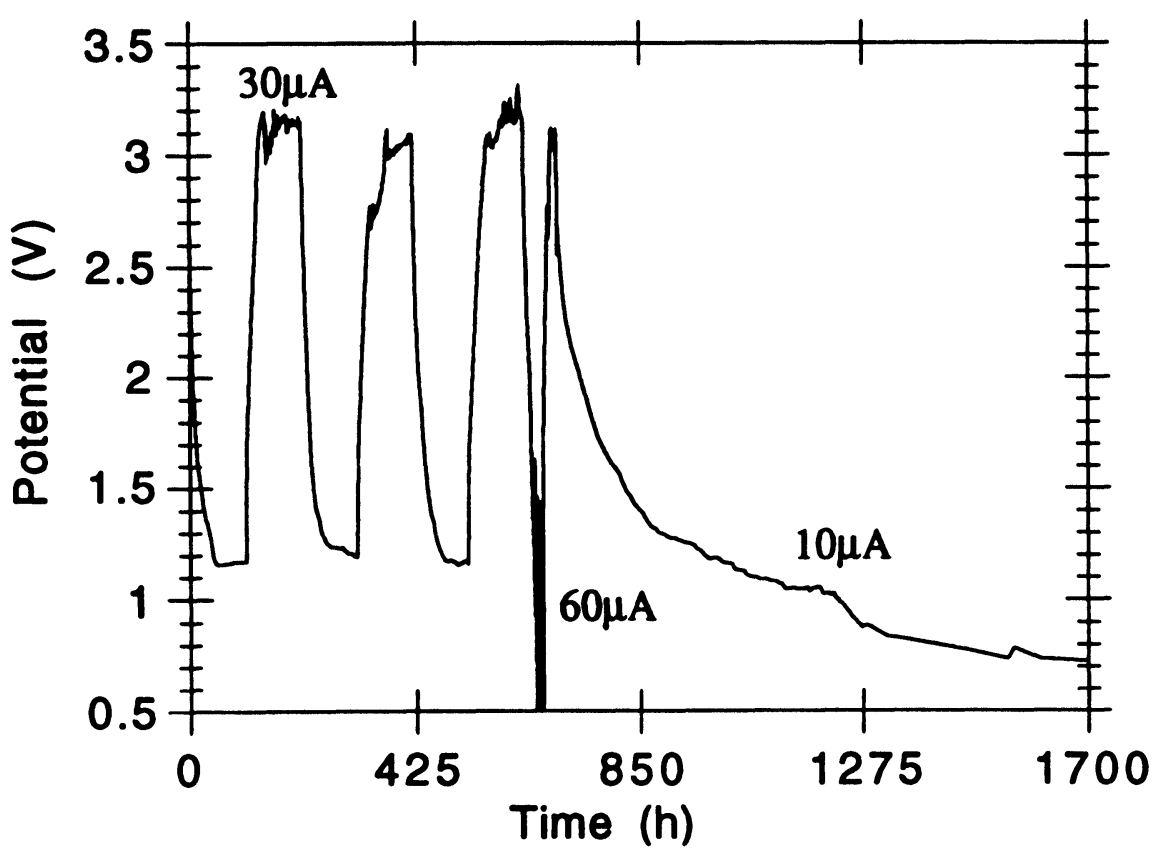

FIGURE 2 Galvanostatic cycle for panthergreek-200 under different current. 


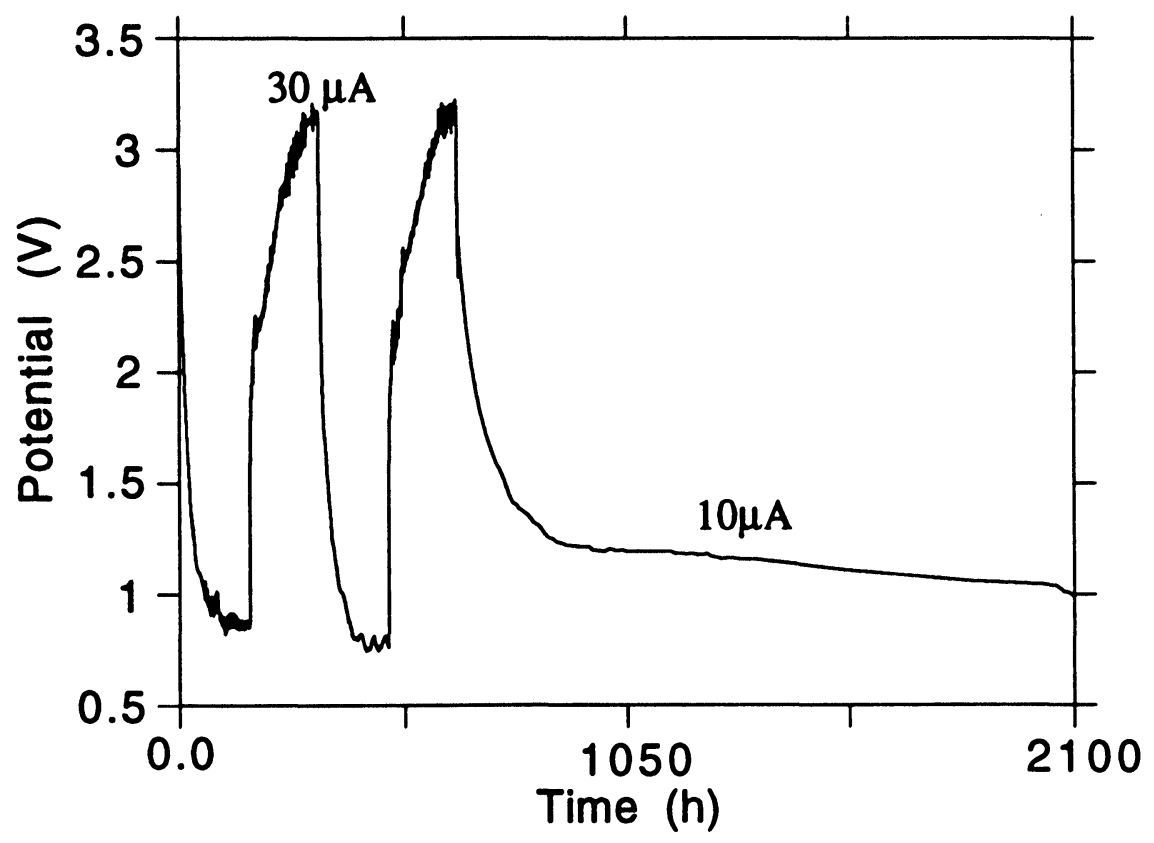

FIGURE 3 Galvanostatic cycle for Superlig under $30 \mu \mathrm{A}$ and $10 \mu \mathrm{A}$.

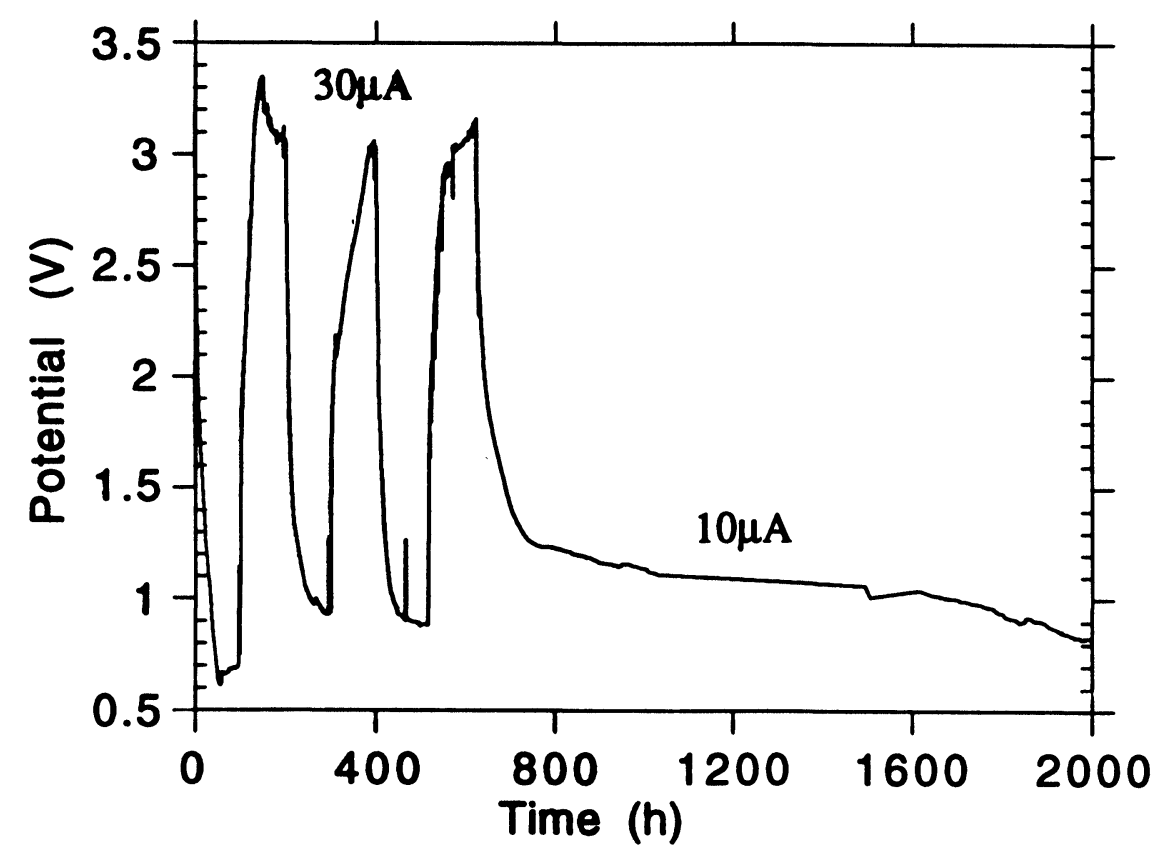

FIGURE 4 Galvanostatic cycle for VSP-200 under different current. 


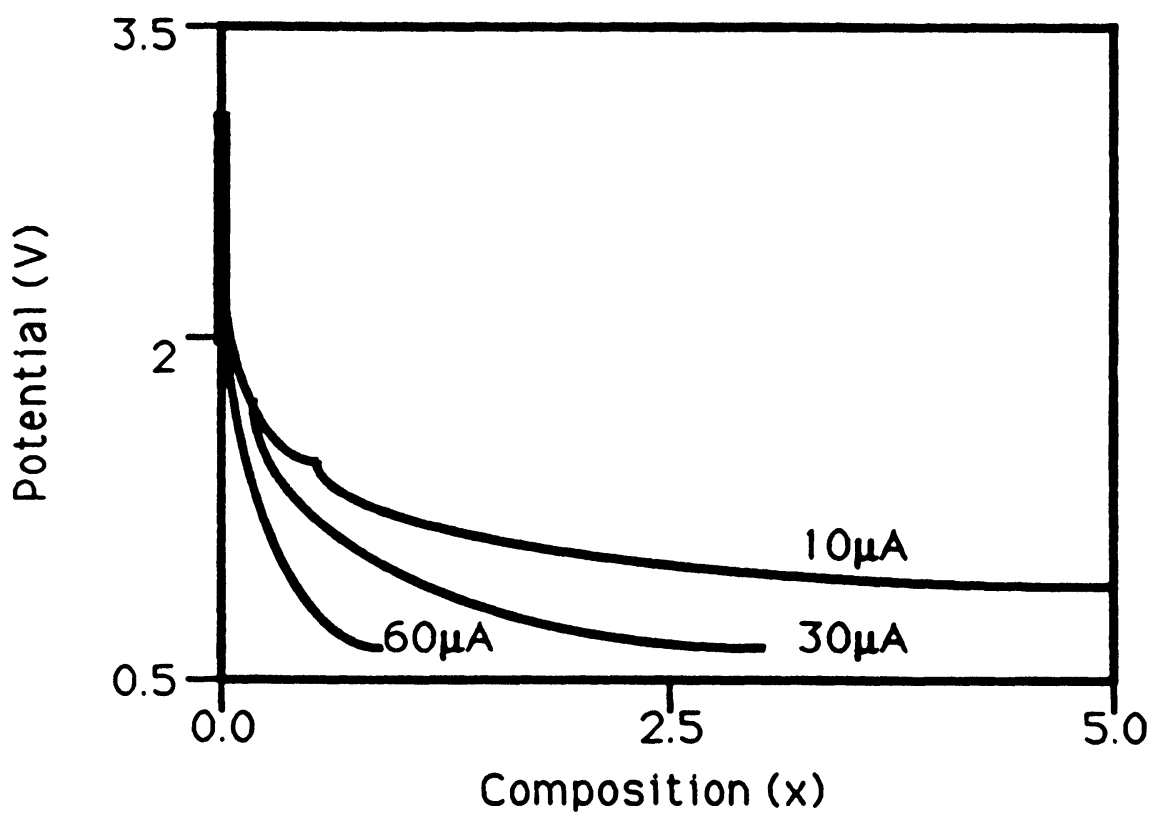

FIGURE 5 Potential vs. composition for Superlig under the different discharge current.

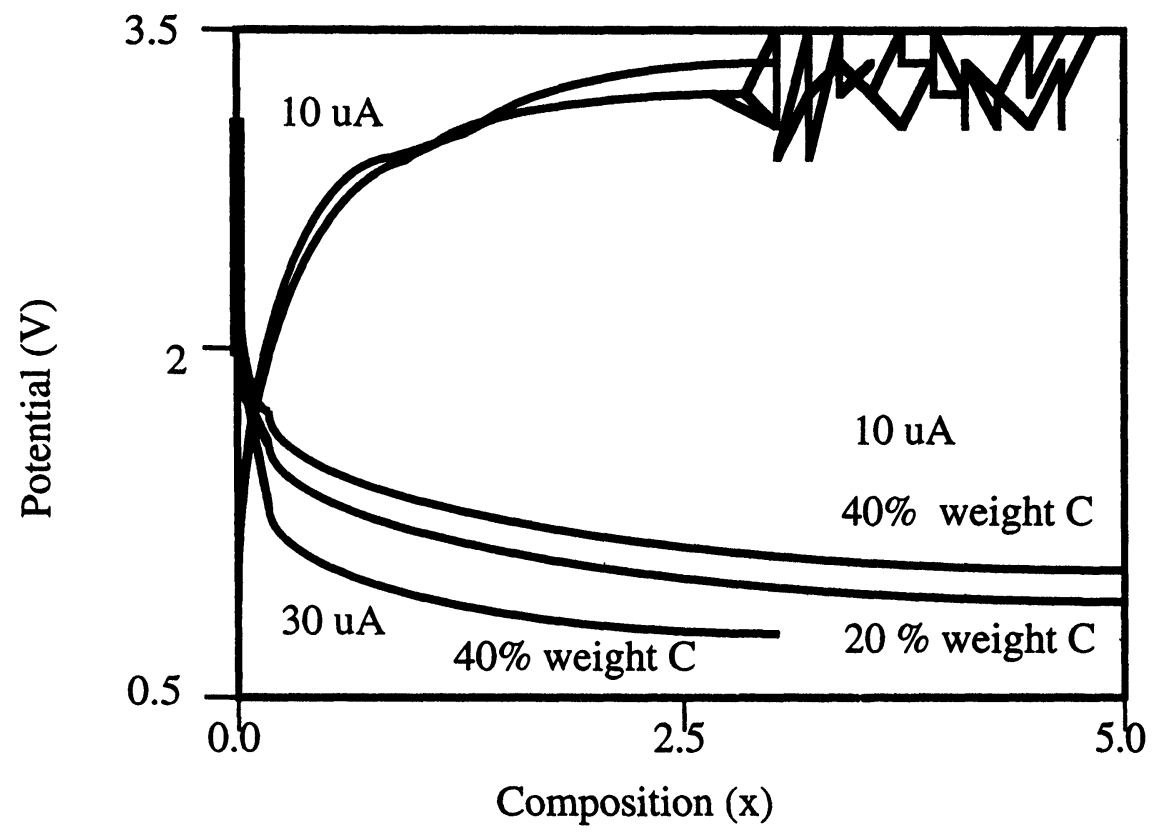

FIGURE 6 The Li galnovastatic insertion and extraction for SPV-200 mixed with $20 \%$ and $40 \%$ weight black carbon under $10 \mu \mathrm{A}$ and $30 \mu \mathrm{A}$ (without $\mathrm{Li}$ extraction curve). 

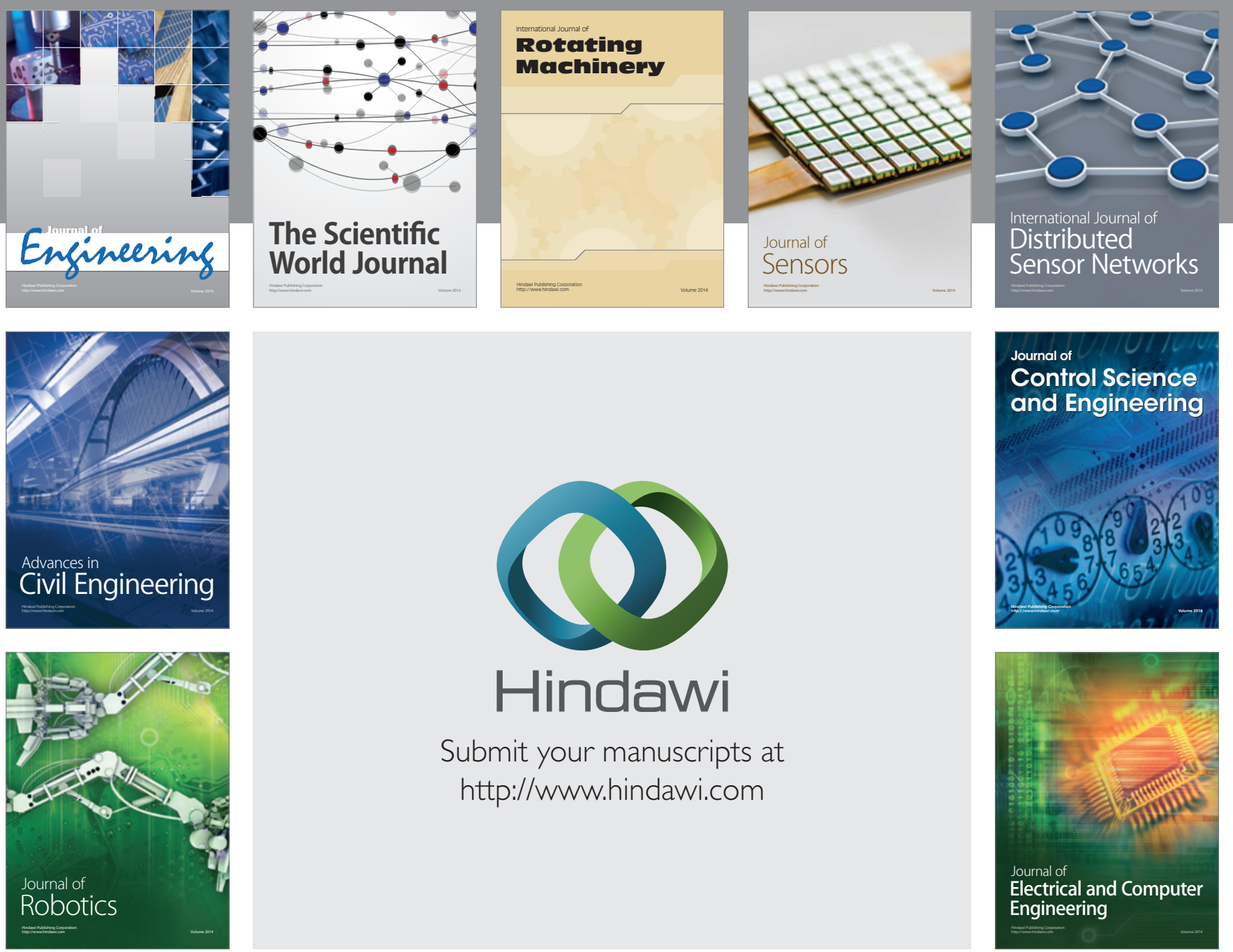

Submit your manuscripts at

http://www.hindawi.com
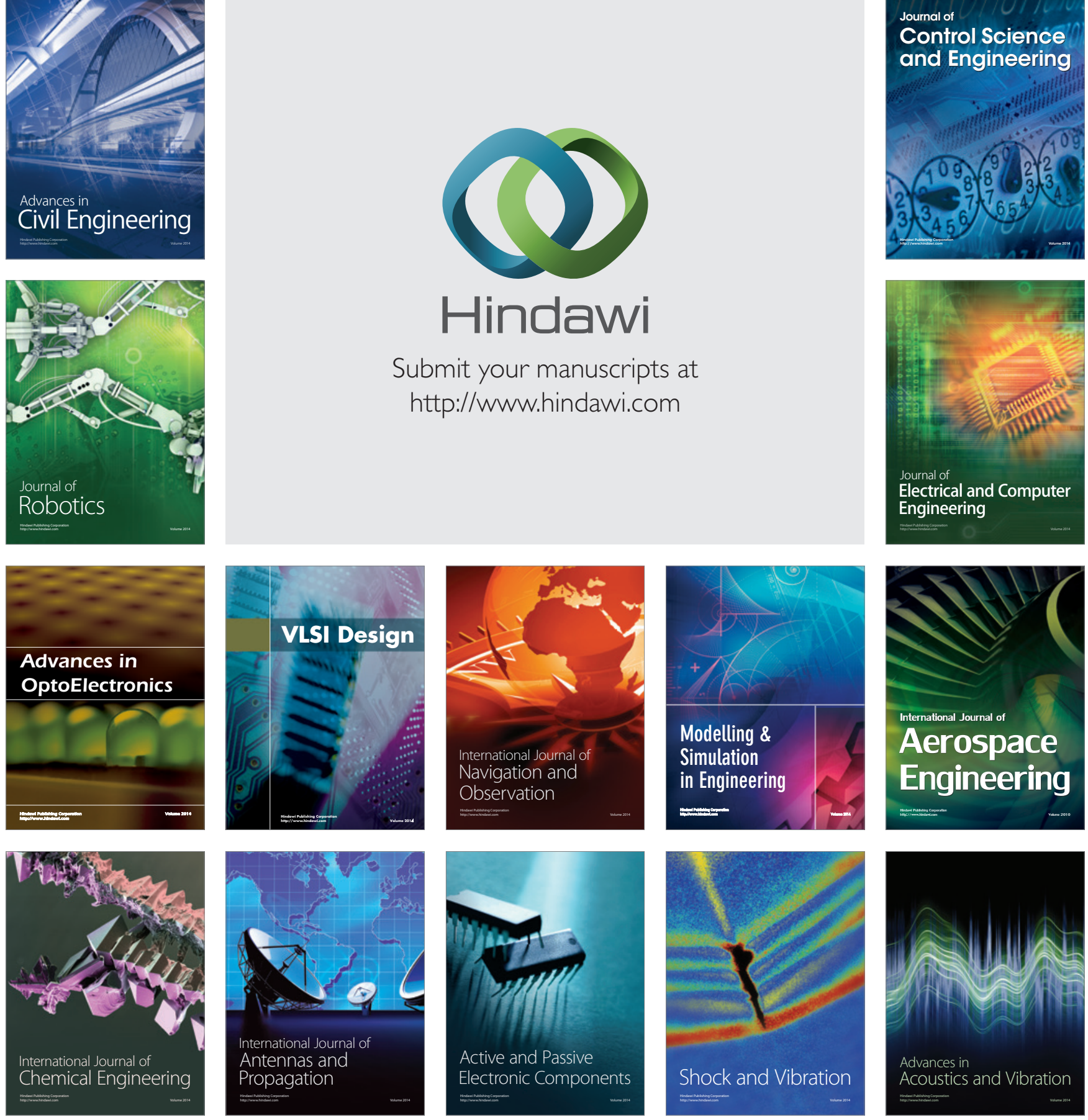